\title{
Using Human Centred Design to Improve Cambodian Communities' Understanding of Water
}

\author{
A pilot in three Cambodian Communities in partnership with \\ Engineers Without Borders Australia and the Cambodian Rural \\ Development Team
}

\section{ABSTRACT}

In 2019, Engineers Without Borders Australia (EWB Australia) piloted the 'Solutions for Sustainable Development' program over six days in three isolated Cambodian communities. This saw a team of professional engineers from Australia provide technical support to EWB Australia's program partner, the Cambodian Rural Development Team (CRDT). The program's objective was to help improve community access to existing CRDT water supply systems, which draw water from the Mekong River. Although EWB Australia has significant experience applying Human Centred Design (HCD) with students, the Cambodia pilot program was the first time using HCD with professionals. The Project Team began by immersing themselves in the communities to understand their challenges, strengths, priorities, expectations and ambitions. To challenge current water usage assumptions and improve water access and reliability, the Project Team utilised design thinking tools, including the use of IDEO's Field Guide to Human Centred Design. Throughout this process, key stakeholders were engaged by EWB via two-way knowledge sharing to help CRDT and the communities develop the necessary skills and tools to improve water access. A final recommendation of the program was for EWB to provide support to CRDT through securing funding initiatives and provision of an in-country professional for long term support to develop CRDT's expertise through a capacity building and strength-based approach.
Keywords: Appropriate Solutions, Empathy Map, Human Centred Approach, Human Centred Design, Strength-Based Approach, Sustainable Development

Year Case Study Was Implemented: 2019

\section{INTRODUCTION}

In Cambodia, a country of 16 million, approximately three million people lack access to safe drinking water. Despite having one of the fastest growing economies in Asia, the country's gross domestic product per capita remains low with a pronounced wealth gap between the country's rich and (often rural) poor (Water.org, 2020). Low access to improved drinking water sources disproportionately affects those in rural areas, which represents $77 \%$ of the Cambodian population (Water.org, 2020). Water-borne illnesses, such as viral and bacterial gastroenteritis, dysentery and cholera are burdens and particularly susceptible are children, the elderly and immunocompromised individuals. Diarrhoea is the second most common inpatient and outpatient diagnosis in Cambodia and the leading cause of death for children under five (Water.org, 2020).

Several Non-Governmental Organisations (NGOs) are working in Cambodia to address water access issues. In February 2019, seven engineers travelled to rural Cambodia with one NGO, Engineers Without Borders Australia (EWB 
Australia), to pilot a new training program which saw the Program Participants work on an existing drinking water challenge with one of EWB Australia's community partners CRDT (Cambodia Rural Development Team). EWB Australia is a member-based not-for-profit community organisation that creates social change through engineering. Since 2003, EWB Australia has focused on developing appropriate engineering solutions through community projects as well as developing skills and knowledge within the engineering sector through education and training programs.

EWB Australia has run projects in Cambodia since 2005, and with CRDT since 2015, when the organisations began partnering on the delivery of the EWB Australia Humanitarian Design Summit Program - a program in which university students participate in a two-week overseas immersive study tour, exploring and applying a humancentred design process with communities and developing associated skills. In 2019, EWB Australia decided to pilot a training program aimed at professional engineers. This pilot was the first iteration of a program developed to expose engineering professionals to community centred design within a development context while supporting EWB Australia's work with a partner organisation.

The pilot program, titled Solutions for Sustainable Development Intensive (S4SDI), was partially inspired by the university student model, but was updated to respond to and leverage the skills of professionals with a number of years' experience within the sector. The pilot was developed with the following aims:

1. Create appropriate solutions for communities that are equitable, feasible, desirable, and viable.

2. Nurture and grow future-ready engineers.

3. Promote community centred practice and embed human centred mindsets within engineering practice.

4. Support EWB Australia's community partners by building the capability and knowledge of the communities through a strength-based approach.

5. Identify and analyse the complex factors contributing to sustainable development.

EWB Australia's pilot program was developed on a request presented by CRDT to improve water access in three isolated Cambodian communities. CRDT is a Cambodian NGO that works with communities around Kratie, Steung Treng and Mondukiri Provinces in the northeast of the country. Since 2001, CRDT has worked to promote livelihood development in communities, while protecting the environment, through projects in water supply, sanitation, agriculture and ecotourism. CRDT takes an integrated approach and works with international partners across the community development and natural resources management space.

In 2017, CRDT procured and installed community scale water systems in several communities along the Mekong Delta to improve and or create new access to water for irrigation. In each system, river water or bore water is pumped to storage tanks using solar pumps automated by a bottom and top water level switch (see Figure 1). Water is gravity fed from the tank to the community household taps via buried reticulation pipework. New connections from the main reticulation line to the household can be purchased by community members should the household lie on the existing line. A water committee within each community was established for the operation and maintenance of the system. The water committees were responsible for financing these activities through collecting payments from the community for water use and establishing new connections and organising repairs.

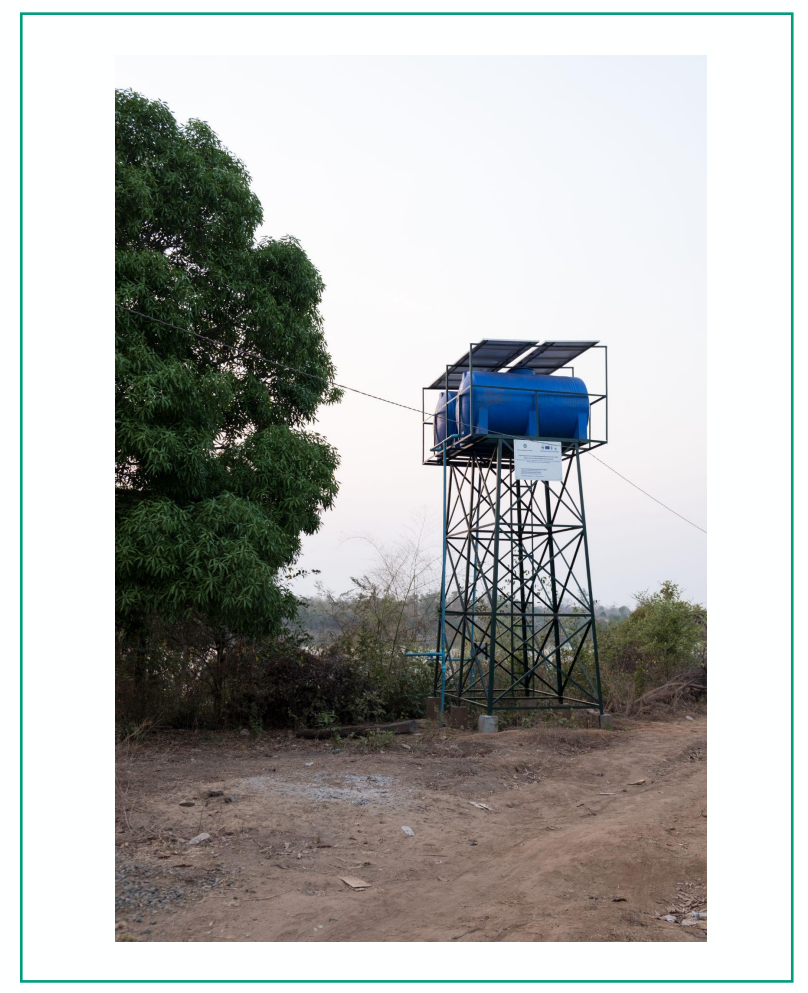

Figure 1 - Community scale water system in Ksach Leav 
Since the installation of these water supply systems, several technical and end-use issues have been experienced. Furthermore, CRDT realised that households were prioritising their water supply for drinking, cooking and bathing rather than the irrigation for which it was initially intended. As a result, CRDT requested assistance from EWB Australia to solve the technical and end-use problems associated with using the existing system in this way.

The pilot S4SDI program saw the Participants work together with EWB Australia staff from Australia and Cambodia, CRDT and local translators as a Project Team over seven days. The case study focused on three communities where water systems had been installed: Koh Dambang, Ksach Leav and Koh Tnout. All three communities are located along the Mekong River, near the border between Kratie Province and Stung Treng Province.

\section{METHODOLOGY - A HUMAN CENTRED APPROACH}

The selected methodology addressed these issues using a human centred approach. This section situates this design philosophy amongst the existing and related communitybased design approaches and describes the methodology for applying a human centred approach.

\section{Adopting a Design Philosophy}

The role of the engineer in providing value to society has been well articulated and is cited in the literature of most associations governing the profession (Smith, J., Anderson, B., Brown, N.J., Colley, A. 2017.). The engineering profession has sought to contribute similarly to international development via organisations with a central focus on the use of engineering to address humanitarian, development, and disaster relief challenges. These include Engineering for Change (EFC) and Engineers for Overseas Development, the EWB network (including EWB Australia), and the RedRs (UNSCO, 2010). In the mid-2010s humanitarian engineering began to emerge as a distinct multi-disciplinary field. Unlike traditional engineering, Humanitarian Engineering focuses specifically on meeting the needs of communities with respect to development and disaster response (Mitcham, C., Munoz, D. 2010.) Humanitarian engineering differentiates itself from more traditional approaches to engineering in that there is an inherent and overarching focus on protecting and promoting human rights and an explicit emphasis on 'doing no harm' (CDA Collective 2004.) As any intervention or action will lead to changes in a community, whether planned or not, there is an emphasis on ensuring interventions are context appropriate and sustainable as well as community driven and owned.

Various methodologies have emerged as valuable tools in the pursuit of this end goal. Amongst these is Human Centred Design (HCD), whose application transcends the humanitarian sector but, given the human perspective embedded in all steps of the problem-solving process, is often utilised in development initiatives. Other tools include community-based development (CBD), community-driven development (CDD) and community-led development (CLD).

All these tools are approaches to implementing development projects that advocate for community participation in decision-making and management (Baldwin, K., Karlan., D, Udry, C. and Appiah, E., 2016). CBD has a focus on using local knowledge and resources to run more effective projects (Woldegiorgis, 2018). CDD takes this a step further by aiming to provide control of the development process, resources and management directly to groups within the community (Kuehnast, de Berry and Ahmed, 2006.) CLD sits alongside CDD on the empowerment end of communityfocused development initiatives; however, it includes an additional focus on fostering connection between members of the community as well as allies outside the immediate networks of the communities to help accelerate change (Loha W. D., 2018.)

All three methodologies include a key set of principles, including:

1. An emphasis on early relationship building through listening to the community and understanding their needs.

2. Establishing the strengths and constraints of the community with respect to the problem at hand.

3. Evaluating the solution to ensure the community's goals have been met and reiterating as necessary.

These approaches are underpinned by the understanding that technical solutions alone are not enough for the longterm sustainability of a development project. Rather, technical solutions may form a part of a larger multifaceted solution. It is not enough for a solution to simply be usable, but it must be desired by the user, and in the case of collaborative design processes, user owned. This philosophy is adopted by EWB Australia using HCD whereby the communities or individuals for which EWB 
Australia is trying to help are at the 'centre' of the design process.

\section{EWB Australia's Human Centred Approach}

EWB Australia believes that achieving lasting social change requires building the capacity of individuals, community organisations and institutions (2020a).

Through developing and strengthening the skills, abilities, processes and resources of people and communities, it enables the people themselves to lead and drive the change they want to see in their communities. This provides people with an opportunity for long lasting sustainable change needed to adapt and thrive in a changing world (EWB Australia, 2020b).

In support of this philosophy, EWB Australia adopts an approach to engineering underpinned by four guiding principles: strengths-based, partnerships, rights-based and human-centred (EWB Australia, 2020c). This approach assumes that there are existing assets within a community group or organisation that can be leveraged to support their development. It is focussed on means and processes, on partnerships and making connections. Thus, a humancentred approach (HCA) to engineering was proposed to understand the issues associated with the CRDT water systems.

EWB Australia (2020c) defines taking a human-centred approach to engineering as:

Placing the expected end-user of a project outcome at the heart and centre of the work from conceptualisation to implementation and on-going operation and maintenance. It places value in their knowledge, experience and expertise to inform, guide or drive the project.

EWB Australia believes that a HCA to engineering supports the development of appropriate, sustainable and scalable solutions. It also requires the participation of people from diverse backgrounds, and the empowerment of these individuals to influence and drive a solution development process. Therefore, this approach aligned with the aims of the S4SDI.

Human Centred Design (HCD) (IDEO Design Kit, 2020) is one of many design processes that can be used to support the design or development of a solution through participatory engagement. It is a people-centric design and management framework where solutions are developed by including people and soliciting feedback at every stage of the process. This ensures the solutions meet the needs of users and empowers them to take ownership of the end result. Rather than pre-determining the specific type of solution, the HCD process reveals the solution, thus removing any bias from initial conjectures.

HCD is not a perfectly linear process. The HCD process adapted by EWB Australia can be separated into six stages that present a simple framework used to introduce people to the fundamental concept and navigate their work:

1. Discover - Starts with understanding the context, discovering community assets and uncovering design opportunities.

2. Empathise - Involves further scoping of the design opportunities from the viewpoint of the user to understand them, the context, user needs and priorities.

3. Ideate-Moves forward from consolidated learnings to explore the possibilities of design.

4. Screen - Design ideas are systematically assessed.

5. Prototype - Prototypes and models are constructed to solicit community feedback. The focus is on prototyping to learn.

6. Communicate - Ideas and models are presented to the community and additional documentation is provided for continuation of the project.

This case study covers the application of these HCD processes to create solutions to the technical issues experienced with the CRDT water systems in rural Cambodia, with an emphasis on the first four stages. The objective was to identify solutions that met the needs of both the users of the water systems, but also CRDT and their community-based ecotourism provider CRDTours (Cambodian Rural Discovery Tours).

Although EWB Australia has significant experience applying HCD with students, the Cambodia pilot was the first time using it with professionals. Furthermore, whilst the S4SDI participants had previous experience in Water and Sanitation Hygiene (WASH) infrastructure, civil engineering, international development and research, they were not necessarily familiar with HCD or its application. EWB Australia thus supported the participants by facilitating an initial training comprising online learning modules that were completed before departure. These were followed by theoretical workshops and in-country cultural awareness training once in Cambodia.

A wide variety of tools and activities can be used to develop a solution using HCD. An overview of the tools and activities used by the Project Team during each of the six 
stages of the EWB Australia HCD process is presented below:

\section{Discover}

A key component of HCD is being able to view a project from the perspective of the communities and individuals who will be influenced by the outcome. For this reason, during the Discover stage the Project Team met with CRDT, before immersing themselves in the communities of Ksach Leave, Koh Tnout and Koh Dambang over several days to engage with key stakeholders through formal and casual discussions, as well as observing the communities in their day-to-day activities.

As EWB Australia's community partner organisation, CRDT had strong existing relationships with each of the communities which provided easy access to a wide variety of representatives from each village. CRDT's intervention was a key contributor to the success of the Discover stage, ensuring prominent figures in the community were available and prepared for the visit. In each community, CRDT assisted the Project Team to coordinate interviews with the village chief and the water committee. The Project Team complemented these interviews with casual discussions with community members encountered during community walks and homestays. In addition, in Koh Tnout, a focus group was organised comprising both men and women from connected and unconnected households.

\section{Empathise}

For this case study Empathy Maps were used during the Empathise stage to synthesise observations and insights uncovered during the Discovery process. Empathy Maps assist in understanding for whom one is designing by defining the stakeholders as customers. The Project Team members responsible for the interviews created a customer profile for each stakeholder using a three-pronged layout populated by what they consider gains, what were their pain points and what tasks or jobs they completed on a daily, weekly or monthly basis (see Figure 2). Thematic analysis was used to simplify Empathy Maps for community members where similar pains or gains were noted.

\section{Ideate}

The ideation stage focused on further developing potential solutions from the learnings captured during the Empathise stage. The Project Team brainstormed together to generate ideas as to how the technical and end-use issues expressed by both CRDT and the water users could be solved. These potential solutions were then mapped into value propositions by considering what solutions could amplify the gains, what solutions could relieve pain points and what products or services could satisfy all of these (see Figure 2).

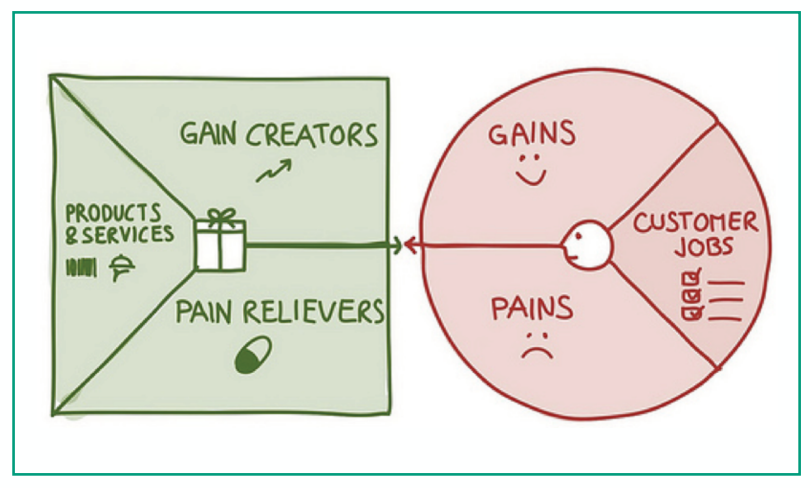

Figure 2 - Empathy Map, (Osterwalder A., 2010)

\section{Screen}

The screening stage required a framework be developed by which the potential ideas could be systematically assessed. The Project Team used the S4SDI program aims as a guide to Screen each value proposition to decide which value propositions offered all the stakeholders the greatest opportunity, with points assigned for each of the program aims satisfied by each proposition.

\section{Prototype and Communication}

Due to the nature of the intensive, the prototyping and communication stages were compressed. The Project Team presented a first round of solutions to CRDT staff for feedback, before iterating on these solutions and presenting to both EWB Australia and CRDT. All recommendations were then delivered to CRDT in the form of a database and report, from which CRDT could further develop and implement the proposed solutions.

In parallel to the solution development process, one of the program aims was also to develop the professional skills of the Project Team members. To measure this development, Program facilitators conducted a number of surveys throughout the duration of the Program to capture the Program Participants individual understanding of the approach and the skills and techniques used. 


\section{HUMAN CENTRED DESIGN IN PRACTICE}

The S4SDI pilot was held in Cambodia from Saturday 23rd February to Sunday 3rd March 2019. The initial training was held in Phnom Penh and included workshops on HCA and the HCD process that would be used to support the subsequent participatory community engagement, as well as an introduction to sustainable development and the Cambodian culture. The latter was co-delivered by the EWB Australia staff from Cambodia, with the aim of allowing the
Project Team to empathise with community members and develop a culturally appropriate work approach.

Following the initial training, as part of the Discover and Empathise stages, a meeting was held with CRDT in Kratie to discuss the challenges CRDT face with regards to the water supply systems and the program more broadly and gain a better understanding of their knowledge of the villages where the water supply systems are installed. Table 1 presents the factors affecting the success of the systems and the program more broadly identified at the meeting:

\begin{tabular}{|c|c|}
\hline CRDT Pains & CRDT Gains \\
\hline $\begin{array}{l}\text { - Limited technical expertise in design and maintenance of } \\
\text { water supply systems. }\end{array}$ & - Experience and capability in engaging with communities. \\
\hline $\begin{array}{l}\text { - Customer water usage varies depending upon homeowner } \\
\text { priorities and circumstances. }\end{array}$ & - Understand community needs and aspirations. \\
\hline $\begin{array}{l}\text { Financial capacity to support community constrained by } \\
\text { drivers of their partner organisations and donors } \\
\text { - Managing expectations and achieving impact. }\end{array}$ & $\begin{array}{l}\text { Understand piped water system is desirable by } \\
\text { community members. }\end{array}$ \\
\hline - Evaluating and communicating outcomes. & $\begin{array}{l}\text { Understand and can sometimes demonstrate water } \\
\text { systems may support improved livelihoods in } \\
\text { communities. }\end{array}$ \\
\hline \multicolumn{2}{|c|}{ CRDT Tasks or Jobs } \\
\hline \multicolumn{2}{|c|}{$\begin{array}{l}\text { Experience in social enterprise development and believe in different approaches to securing sustainable markets for the } \\
\text { produce from the home/community gardens. }\end{array}$} \\
\hline
\end{tabular}

Table 1 - CRDT Empathy Map 
To also view the project from the point of view of the communities, the Project Team subsequently immersed themselves in the three villages and engaged with a variety of community members over several days. The aim of the community engagement was to get a better appreciation of the challenges, strengths, priorities, expectations and ambitions of the community members, as well as to understand the existing water supply systems and how they are used. Various methods of community engagement were used in the villages, such as:

- Discussions with village chiefs and water committees.

- Focus groups with community members.

- Community walks and observing the community.

- Casual conversations with community members in their daily environment.

CRDT played an important role in facilitating the community engagement, using their existing relationships to arrange meetings with those who were involved in the development and maintenance of the existing water supply systems, as well as preparing the communities more generally for the visit of the Project Team. This enabled the communities to be ready ahead of time for providing feedback on how the water systems had been operating and improvements that they thought could be made to benefit their community.

To get a variety of perspectives from the community, the Project Team was also given the opportunity to engage with the community more freely with the assistance of translators. As two communities have an established eco-tourism industry through CRDTours, certain community members are familiar with regular visitors, and even hosting participants from prior EWB student programs.

However, as part of their participation in the CRDTours program, many of these households are connected to the water system. As such, during community walks, other members of the communities were also solicited for their views through more informal conversations. When asked to be interviewed, many community members were accommodating and willing to participate. Typical interviews were short and focussed on using empathetic language to understand how individuals use water at home and the impacts that water has on their health and ability to earn money.

Focus group sessions were also conducted during the community visits, where a range of activities were used to encourage participation and engagement. In Koh Tnout community members were asked to describe how they prioritised their water use each day by dividing the water from one bottle between several glasses labelled depending on the use This activity visually demonstrated their attitudes around using water. An image of this activity in action can be seen below in Figure 3. Not only were the Program Team more readily able to understand how they prioritised this water each day, but this also facilitated discussions around how they stored, prioritised and used water throughout the day for different activities.

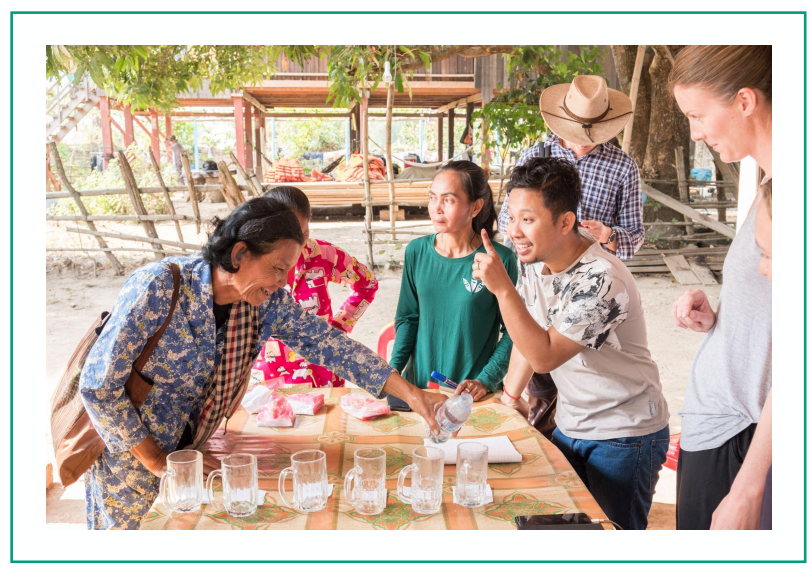

Figure 3 - Focus group activity in Koh Tnout

Following the community immersion, Empathy Maps were created for individual communities and focus groups to synthesise the Project Team's observations and insights from their conversations whilst in the community. Table 2 presents the collective pains and gains of the existing water systems identified by the community members of Ksach Leave, Koh Tnout and Koh Dambang, comprising a collective summary of the conversations from each community: 


\begin{tabular}{|c|c|}
\hline Collective Communities' Pains & Collective Communities' Gains \\
\hline $\begin{array}{l}\text { Water systems did not provide sufficient water for all } \\
\text { connected households. }\end{array}$ & $\begin{array}{l}\text { - Water system household connections better accommodate } \\
\text { CRDTours' eco-tourism guests. }\end{array}$ \\
\hline $\begin{array}{l}\text { No overnight water supply. Unsuitable for agricultural or } \\
\text { farming uses early in the morning or late in the day forcing } \\
\text { community members to store all necessary water during } \\
\text { the day. }\end{array}$ & $\begin{array}{l}\text { Less time spent retrieving water from river enabling } \\
\text { income generating activities such as farming or fishing. }\end{array}$ \\
\hline $\begin{array}{l}\text { - Geographical challenges in connecting all households to a } \\
\text { single water system. }\end{array}$ & $\begin{array}{l}\text { Water systems remove the physical challenges associated } \\
\text { with water collection. }\end{array}$ \\
\hline $\begin{array}{l}\text { - Intermittent damage to pipework affects system reliability } \\
\text { No standardised system repairing breakages although } \\
\text { local masons may have capability to maintain and repair } \\
\text { system. }\end{array}$ & $\begin{array}{l}\text { No reported issues with money collected from community } \\
\text { by water committee for maintenance works. }\end{array}$ \\
\hline $\begin{array}{l}\text { Water system connection fees ( USD } \$ 45) \text { are a barrier to } \\
\text { some households connecting while other households pay } \\
\text { because of the convenience. } \\
\text { Reported confusion around tiered pricing schemes which } \\
\text { is applied differently between communities. }\end{array}$ & $\begin{array}{l}\text { Community savings groups have shown potential to help } \\
\text { villagers to save for connection to the water supply } \\
\text { systems. }\end{array}$ \\
\hline $\begin{array}{l}\text { All three villages faced general sanitation challenges, } \\
\text { including lack of access to latrines, consumption of river } \\
\text { water without treatment and contamination through poor } \\
\text { storage. }\end{array}$ & $\begin{array}{l}\text { Overall, good community WASH practices were observed. } \\
\text { Households willing to boiling water and/or filter water (if } \\
\text { they have existing filters) before drinking. } \\
\text { - General education programs have developed health and } \\
\text { hygiene awareness amongst the communities. }\end{array}$ \\
\hline \multicolumn{2}{|c|}{ Collective Communities' Tasks or Jobs } \\
\hline \multicolumn{2}{|c|}{$\begin{array}{l}\text { - Farming (cashews, rice, vegetables, chickens, cows, pigs) and fishing. } \\
\text { - Home gardens (fruit and vegetables). } \\
\text { - Accommodating guests through CRDTours' eco-tourism programs. }\end{array}$} \\
\hline
\end{tabular}

Table 2 - Collective Communities' Empathy Map 


\section{PROGRAM OUTCOMES}

By grouping the collective communities' pains and those of CRDT, the Project Team identified the following key impact areas:

- Reliability of water supply.

- Accessibility of water supply.

- Water quality for drinking.

- Learnings/skills development of CRDT and EWB Australia relationship.

Based on the meetings with CRDT and the visits to the beneficiary communities, there was an immediate need to provide a reliable and adequate water supply to current users of the system. A significant challenge for CRDT was understanding the technical design, capacity and limitations of the existing water system. In a first round of Ideation, the Project Team identified potential short-term solutions or considerations to address these Pains and communicated them to CRDT to potentially implement if practicable.

Solutions focussed on making minor modifications to the technical design of existing pumps, tanks, pipes and power supplies to improve the communities' access to river water.

Nevertheless, it was recognised that implementing these solutions would not necessarily lead to success for future projects. There was a need to explore the appropriate technology and systems to sustainably serve the needs of the communities. Furthermore, one of the main drivers of design decisions of the existing systems was the available budget provided by partners and donors to CRDT. As such, the needs of the community, capacity and functionality requirements were secondary, limiting the suitability of the systems.

Based on this feedback, in a second round of Ideation, the Project Team proposed long term solutions and approaches to provide CRDT and the communities with future opportunities for development in a second phase. These solutions capitalised on the existing Gains or strengths identified within CRDT and the communities during the Emphathise phase and included the exploration of new technical solutions and funding and delivery models for the development of sustainable water infrastructure. These opportunities are presented in Table 3.

\begin{tabular}{|l|l|}
\hline \multicolumn{1}{|c|}{ Key Impact Areas } & \multicolumn{1}{|c|}{ Long Term Solutions/Approaches } \\
\hline Reliability of water supply & $\begin{array}{l}\text { - Alternative water systems specific for agriculture. } \\
\text { - Redesign of water systems considering climate change, relocation, } \\
\text { decentralization. }\end{array}$ \\
\hline Accessibility of water supply & $\begin{array}{l}\text { - Incorporate alternative/improved water supplies (rainwater, more pumps, bigger } \\
\text { tanks). }\end{array}$ \\
\hline Water quality for drinking & $\begin{array}{l}\text { Alternative community money collection systems. } \\
\text { - Social enterprise for water sales. }\end{array}$ \\
\hline Learnings/skills development of & $\begin{array}{l}\text { - Incorporate complimentary de-/centralised treatment. } \\
\text { - Improved sanitation reducing source contamination. }\end{array}$ \\
\hline CRDT & $\begin{array}{l}\text { - Incorporate WASH into the program. } \\
\text { - Increase two-way knowledge sharing between CRDT and CRDTours. } \\
\text { - Explore market-based business models and alternative cost structures. } \\
\text { - Explore alternative funding sources. }\end{array}$ \\
\hline
\end{tabular}

Table 3 - Proposed long term approaches to solving the issue 
These propositions were then screened against the program aims. Table 4 presents the results of this screening process. The process identified that the only solution which satisfied all the program aims was the learning and skills development of CRDT.

\begin{tabular}{|c|c|c|c|c|c|c|}
\hline \multirow{2}{*}{ Key Impact Areas } & \multicolumn{6}{|c|}{ Program Aims } \\
\hline & 1 & 2 & 3 & 4 & 5 & Total \\
\hline Reliability of water supply & $x$ & & $x$ & & $x$ & 3 \\
\hline Accessibility of drinking water & $x$ & & $x$ & & & 2 \\
\hline Water quality for drinking & $x$ & & & $x$ & $\mathrm{x}$ & 3 \\
\hline $\begin{array}{l}\text { Learning/skills development } \\
\text { of CRDT }\end{array}$ & $x$ & $x$ & $x$ & $x$ & $x$ & 5 \\
\hline
\end{tabular}

Table 4 - Screening of the proposed long-term approaches to solving the issues

1. Create appropriate solutions for communities that are equitable, feasible, desirable and viable.

2. Nurture and grow future-ready engineers.

3. Promote community centred practice and embed human centred mindsets within engineering practice.

4. Support EWB Australia's community partners by building the capability and knowledge of communities through a strength-based approach.

5. Identify and analyse the complex factors contributing to sustainable development.

\section{ONE UNDERPINNING APPROACH}

From following the HCD process, the Project Team recognised that the water system design, procurement and decision map tools recommended for the installation of future water systems would not be appropriate for CRDT without technical engineering training and financing sourcing support. Indeed, implementation of the short- and long-term solutions and approaches required enabling CRDT to act independently on these recommendations. Through the Discover and Empathise stages, it was demonstrated that CRD already had experience in engaging with communities and understanding their needs. However, they lacked the technical expertise and financial capacity to address them. The development of CRDT's capabilities and expertise through training and technical support represented an underpinning approach to addressing a number of both the short- and long-term recommendations.

EWB Australia provides field placement engineers whereby professionals from Australia are placed in local communities within Cambodia, assisting these communities to gain access to the knowledge, resources and appropriate technologies they need to improve their livelihoods. It was recommended that field professionals work on placement with CRDT to help develop the necessary tools for improving on existing or developing new water supply systems and deliver the upgrades, whilst training CRDT in using these tools and methods. By supporting the local CRDT team members, solutions developed are more desirable and viable as they are inherently centred on the needs of CRDT and the communities. The knowledge and skills transferred to CRDT by the field professional also allows CRDT team 
members to be ready for future projects. This combination of tools and support by a field professional will lead to the development of sustainable outcomes by building the capability and knowledge of CRDT through a strength-based approach.

In addition, it was recognised that EWB Australia could provide ongoing support to CRDT in professional areas. Professional areas of support focus on providing CRDT grant writing and fund sourcing assistance, a major pain of CRDT identified by the Project Team. This is reflected in the available budget provided by donors and partners in conjunction with the pressure of demonstrating the impact of their donations (see table 1). Often the needs of the community, capacity and functionality requirements of the system were neglected as a consequence. Both parties (EWB Australia and CRDT) are aware of this challenge and are now working under a Memorandum of Understanding (MOU) to assist in grant writing and fund sourcing based on CRDT's existing record in the communities, proving the added value that each of the two organisations brings in the partnership.

The S4SDI aimed not only at developing EWB Australia's community partners, but also providing the S4SDI participants with the opportunity for personal and professional development. The program enabled participants to engage in projects which have a net positive potential, leading to the development of equitable and sustainable solutions. Participants gained valuable skills in human centred approaches, teamwork and empathetic stakeholder engagement. Based on the surveys conducted by program facilitators throughout the process, a majority of the Program Participants noted first impressions of suitable solutions for the issue were vastly different from those identified through the application of the HCD approach, and they also reported a step change increase in use and understanding of a human-centred mindset in their post project survey.

Insights into CRDT and the local community's context and challenges enabled the fostering of a stronger relationship with the community partner organisation CRDT, which was a major and positive outcome for EWB Australia. Overall, the pilot program was considered a success by EWB Australia and acted as a precursor for ongoing programs in which industry professionals will be taken on in-country intensives. Furthermore, the close relationship fostered between CRDT and EWB Australia will help EWB Australia identify the complex challenges facing CRDT and the communities, which in turn helps EWB support CRDT using appropriate approaches. In return, access to the communities supported by CRDT allows EWB to train future-ready engineers by providing experience to lead development projects and utilise the HCD process.

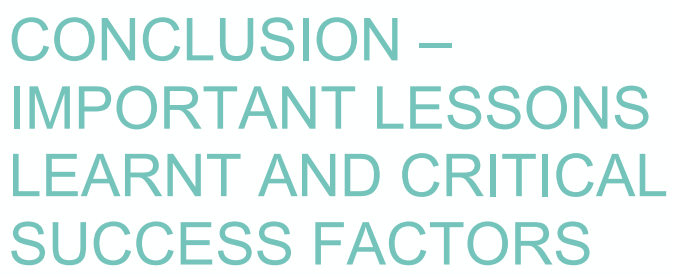

By carefully assessing the needs and challenges of both CRDT and the communities of Ksach Leave, Koh Tnout and Koh Dambang through the HCD process, the Project Team was able to develop not only a deeper understanding of the challenges faced by CRDT and the communities in which they work, but also their strengths. It was discovered that many of the technical issues with the community water systems were in fact symptoms of deeper challenges. Whilst CRDT understood the needs and aspirations of the communities, they faced constraints in the support they could provide due to the drivers of their partner organisations and donors, as well as evaluating and communicating outcomes. The design of the existing systems was therefore heavily influenced by the available budget and hence CRDT's funding constraints. Furthermore, due to their limited technical expertise, CRDT were also forced to rely on local contractors to specify, design and install systems which they could not validate ahead of time.

Following the Human Centred Approach was successful in allowing solutions identified to be appropriate for both CRDT and the communities who will be impacted by any changes proposed for the water supply systems. The practice of immersion in this program enabled the Project Team to efficiently understand how the water supply system impacted the livelihoods of each of the communities. The Empathy Maps were also a fundamental tool in the process, helping to provide background where assumptions may have otherwise been used.

Although the Project Team had the potential to independently solve the technical issues associated with the existing community water systems, the HCD process indicated that without addressing CRDT's deeper challenges around funding and technical capacity, CRDT and the communities in which they work will continue to be disadvantaged by these obstacles. Thus, it was determined that the most effective and sustainable solution was to develop CRDT's expertise through a capacity building and 
strength-based approach. This is reflected in the on-going relationship between EWB and CRDT with the mobilisation of two field professionals in 2021 to further improve upon the existing water supply systems, and the professional services support which EWB provides under the MOU. Whilst this relationship was developed over several years of interactions between EWB Australia and CRDT, the seven days the Project Team spent collaborating with CRDT in country played a significant role in reinforcing and honing it.

A number of limitations should be noted that had an impact on the effectiveness of this program to achieve its desired outcomes. Although these limitations did not prevent the development of a solution, there may have been an opportunity to develop each of the identified solutions further.

A key constraint on the program was insufficient time, restricting the Prototype and Communicate phases of the HCD process.

Furthermore, there was insufficient time to involve communities in the Ideate and Screen phase, who may have been able to provide key insights and feedback to further inform the final solution. Although these steps of continuous involvement of the community were not able to be conducted during the Program, given CRDT's previous engagement with the communities and by further developing CRDT's skills, it was deemed sufficient that this process would be continued independently beyond the Program.

By placing community needs and aspirations first, and adopting a human centred approach, there is an opportunity to develop sustainable water infrastructure in communities like Ksach Leave, Koh Tnout and Koh Dambang and beyond. Furthermore, as the Program Participants reported an increased uptake of program tools in their post program survey, it's expected that they will continue to leverage these tools in their future careers.

\section{REFERENCES}

Baldwin, K., Karlan., D, Udry, C., Appiah, E., 2016. Does Community-Based Development Empower Citizens? Evidence from a Randomized Evaluation in Ghana. Cambridge: Ma.

CDA Collaborative Learning Projects 2004. Analyzing the Impact of Assistance on Conflict: A Handbook. Cambridge, MA: CDA Collaborative Learning Projects.
Engineers Without Borders Australia 2020a, About Us [online], Melbourne, Australia, last updated 2020, viewed 1/02/2020, https://www.ewb.org.au/about/

Engineers Without Borders Australia 2020b, Our Community Approach [online], Melbourne, Australia, last updated 2020, viewed 1/02/2020,

https://www.ewb.org.au/our-impact/our-communityapproach/

Engineers Without Borders Australia 2020c, Technology Development [online], Melbourne, Australia, last updated 2020 , viewed $1 / 02 / 2020$,

https://www.ewb.org.au/project/technology-development/

IDEO 2020, HCD: The Human-Centred Design Kit [online], San Francisco, USA, last updated 2020, viewed 1/02/2020, https://www.ideo.com/post/design-kit

Kuehnast, K., de Berry, J. and Ahmed, N., 2006.

Community Driven Development in the Context of ConflictAffected Countries: Challenges and Opportunities. Washington, USA : The World Bank.

Loha W. D., 2018. Community-Led Development: Perspectives and Approaches of Four Member Organisations. Washington, USA: SIT Graduate Institute.

Mitcham, C., Munos, D. 2010. Humanitarian Engineering. San Rafael, USA: Morgan \& Claypool Publishers.

Osterwalder A., 2010. Business Model Alchemist, Hoboken, New Jersey USA, John Wiley \& Sons, Inc.

Smith, J., Anderson, B., Brown, N.J., Colley, A., 2017. The Rise of Humanitarian Engineering Education in Australasia. Manly, Australia: Conference: Annual conference of the Australasian Association of Engineering Education.

UNESCO, 2010. Engineering: issues, challenges and opportunities for development. Paris: UNESCO Publishing.

Water.org 2020, Cambodia's water and sanitation crisis [online], Kansas City, Missouri, United State, last updated 2020, viewed 1/02/2020, https://water.org/ourimpact/cambodia/

Woldegiorgis. T., 2018. Community Driven Development (CDD) vs Community Based Development (CBD) for Practitioners and Development Actors. 


\section{THE AUTHORS}

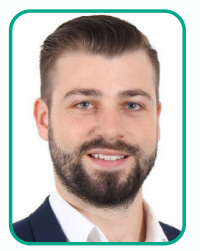

\section{Andreas Henschke}

As a highly motivated and qualified

Mechanical Engineer Andreas has directed his interest and passion to engaging in water industry projects to develop equitable and sustainable solutions. Andreas combines his passions for science and humanitarian work through an active involvement in various industry groups such as Engineers Without Borders.

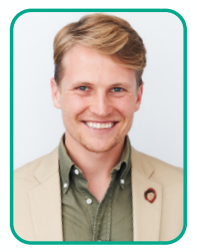

\section{Jeff McAllister}

Jeff McAllister is a writer and chemical engineer who is passionate about creating a more equitable world through safer, more reliable and accessible water services. Jeff specialises in water and wastewater treatment and writes about issues at the nexus of humans, water and the environment.

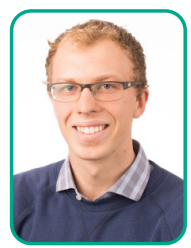

\section{Simon Harbig}

Simon is an Engineering Geologist with over 6 years' industry experience. Simon has participated in various volunteer roles for EWB and Pollinate Group and in 2019 Simon participated in the pilot "Solutions for Sustainable Development Intensive" with EWB Australia in Cambodia.

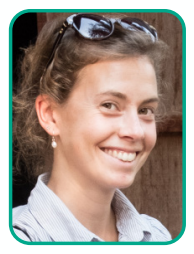

\section{Stephanie May}

Stephanie is a Civil Engineer with over 6 years' international experience across the private and non-government sectors, with a focus on infrastructure projects and humanitarian engineering. In 2019 Stephanie participated in the pilot "Solutions for Sustainable Development Intensive" with EWB Australia in Cambodia and has followed this up with remote volunteering. 